\title{
Computational Investigation on Substituent and Solvent Effects on the Electronic, Geometric and Spectroscopic Properties of Azobenzene and Some Substituted Derivatives
}

\author{
Isaiah Ajibade Adejoro, Oluwatoba Emmanuel Oyeneyin*, Babatunde Temitope Ogunyemi \\ Department of Chemistry, University of Ibadan, Oyo State, Nigeria
}

Email address:

ajibadejoro@yahoo.com (I. A. Adejoro), emmanueltoba90@gmail.com (O. E. Oyeneyin), btogunyemi@yahoo.com (B. T. Ogunyemi)

To cite this article:

Isaiah Ajibade Adejoro, Oluwatoba Emmanuel Oyeneyin. Computational Investigation on Substituent and Solvent Effects on the Electronic, Geometric and Spectroscopic Properties of Azobenzene and Some Substituted Derivatives. International Journal of Computational and Theoretical Chemistry. Vol. 3, No. 6, 2015, pp. 50-57. doi: 10.11648/j.ijctc.20150306.12

\begin{abstract}
Computational investigation on the ground state properties of trans-azobenzene and four kinds of hydroxy-ended azobenzene-type chromophores containing different substituent groups as electron donor and acceptor in different solvent media was carried out. The effects ofsubstituents $-\mathrm{I}_{2},-\mathrm{OH}^{-}$and $-\mathrm{CH}_{3},-\mathrm{NH}_{2}$, and $-\mathrm{Cl}_{2}$ on the electronic properties like the $\mathrm{E}_{\mathrm{HOMO}}, \mathrm{E}_{\mathrm{LUMO}}$, band gap, dipole moments, global hardness, electrophilicity indices were studied using the $A b$ initio restricted DFT self-consistent field method with the Becke Three Lee Yang Parr (B3LYP)/6-31G* method in vacuum, water, diethylether, ethanol and acetone. The results showed that these properties were altered upon substitution with different groups. The azobenzene gave a slight difference in its band gap in different solvent changing from (3.95 eV) in vacuum to the lowest $(3.87 \mathrm{eV})$ in acetone but changes drastically as we introduce different substituents. It was also found that the dipole moment $(\mu)$, polarizability $(\alpha)$, absorption wavelength $\left(\lambda_{\mathrm{ab}}\right)$ gave slight change in different solvents but rapidly increased as the band gap reduces, invoking their reactivities. They are also red-shifted as different substituents are added. Of all the studied molecules, compound $\mathrm{H}$ gave the lowest band gap of $0.46 \mathrm{eV}$, the highest dipole moment $(875.02 \mathrm{D})$, the highest polarizability $\left(64.97 \mathrm{C} . \mathrm{m}^{2} \mathrm{~V}^{-1}\right)$ and it is the most red-shifted $(401.13 \mathrm{~nm})$. Molecule $\mathrm{H}$ therefore, has the lowest band gap, highest polarizability and dipole moment. It also has the highest molecular size and the highest planarity. This means that the molecule is the most reactive, most polarizable, highest electro-optic response and it is the softest.
\end{abstract}

Keywords: Molecular Structure, Azobenzene, Solvent Effects, Band Gap,

Ab initio Restricted Hf-Dft Self-Consistent Field Calculations, Dipole Moment

\section{Introduction}

The importance of azo-dyes organic compounds, among all other colourants cannot be over emphasized owing to their various applications [1]. Azobenzene is the simplest example of the various theoretically and pratically important class of organic dyes [2]. They are used in traditional textile applications such as in the dyeing of textile fibres, plastics, leathers, paper and biomedical studies[3,4], they are capable of producing different high intensity colors such as yellows, oranges and reds more readily because of their $\pi$ delocalization $[5,6]$. Methyl orange and disperse orange are examples of such azo compounds. Azobenzene exists mainly as the trans-isomer, this is because the cis-isomer is less stable than the trans-isomer. The trans-isomer can be converted to the $c i s$-isomer upon photolysis [7]. Azobenzene molecules can be incorporated into polymer matrices as stabilizers. Recently, electronic industries have employed the use of dyes as colorimetric sensors and NLO devices [8,9].

Unsubstituted trans-azobenzene has a low intensity $\mathrm{n}-\pi^{*}$ (occurs near $450 \mathrm{~nm}$ and is symmetry forbidden and less intense) absorption in the visible region and a higher intensity $\pi-\pi^{*}$ (occurs near $320 \mathrm{~nm}$ and is symmetry allowed) absorption in the near ultraviolet region while those that are ortho- and para- substituted with electron donating groups like the amino azobenzenes closely space the $n-\pi^{*}$ and $\pi-\pi^{*}$ bands in the violet or near-visible UV due to an increase in the $\pi$ orbital energy and a decrease in the energy of the $\pi^{*}$ 
orbital. Chromophores having a donor-acceptor $\pi$-charge transfer structure exhibit high molecular hyperpolirizability ( $\beta$ ) [10]. Substitution of the 4 and 4' positions of the two azo rings with electron withdrawing and electron donating groups causes a push-pull configuration in a strongly asymmetric electron distribution, leading to a pronounced increment in the value of $\beta$.

The compound of interest is trans-azobenzene whose properties were investigated in vacuum and other solvents. Different kinds of hydroxy-ended azobenzene chromophores containing different electron withdrawing and electron donating substituents [10] were also considered.

Azobenzenes and its derivatives are aromatic in that they obey the aromaticity rule because they are cyclic, planar, and $\mathrm{sp}^{2}$ hybridized. Addition of substituents to a molecular structure leads to great variations in the properties like stability, optical electronic properties such as the band gap, electron affinity, ionization potential and other properties of the molecules [11] and particularly alters the electric dipole moment $(\mu)$ of the molecule [23]. These changes however, might also occur if the molecules is effected by the environment, for instance, a solvent medium can shift the absorption spectrum which can greatly alter the electronic properties of the molecules $[12,13]$. It was observed that the ground state molecular geometries, dipole moments and polarizabilities of some aniline derivatives were associated with a decrease in the band gap upon substitution or with the presence of a solvent $[14,48]$. The theoretical investigation on the ground state properties of isomeric benzofused thieno [3, 2-b]furans was carried using the semi-empirical AM1 and Density functional theory with bias with the B3LYP using the $6-31 \mathrm{G}^{*}$ basis set and it was observed that substituents like $\mathrm{Br}_{2}, \mathrm{I}_{2}$ and $\mathrm{OH}^{-}$alter the properties, stabilities and reactivities of the isomers [15].

Owing to the $\pi$-delocalization of these molecules, there is a redistribution of electronic charge across the entire length of conjugation under the influence of an external electric field, which should increase vastly for the functionalized molecules (having electron donating and electron withdrawing groups at the 4 and 4' positions. The intra-molecular charge transfer (ICT) is an important process which focuses on systems in which the donor and acceptor groups are directly connected through a single or $\pi$-bond. These azobenzenes can be incorporated into self-assembled monolayers and superlattices [16], sol-gel silica glasses [17], various biomaterials [18], nonlinear optical devices [10]. Azobenzenes have been attached to some molecules in order to control their properties; this is due to the photochromic and photoswitchable natures of the azobenzenes. It has been reported to attach to cyclodextrins [19, 20], organometallic ferrocene polymers [21], dendrimers [22] among others.

As earlier mentioned, experimental dipole moments have been used to describe and measure the electron distribution. Meaning that adding substituents to the azobenzene chromophores can greatly alter the dipole moments as well as the polarizabilities therefore, invoking both IR and Raman activity simultaneously [24]. Another way to predict the both the intra-molecular and inter-molecular charge transfer is through the natural bond orbitals (NBOs) of molecules, with the intra-molecular interaction due to the overlapping of the bonding and the anti-bonding orbitals [25].

A lot of experimental and theoretical work have been used to study the nonlinear optical properties of inorganic and organic molecules with the later having a lot of advantages in that they are easier to synthesize, posses higher electrical conductivity, presence of delocalized electrons and possession of better mechanical properties. So, quantum chemical studies on molecules such as azobenzene and its derivatives will be carried out to understand their various properties and investigate the influence different solvent media and substituents play on these properties. It will enable researchers who are interested in synthesizing similar molecules of the same properties have a prior knowledge about them prior synthesis. It also allows for chemical tunability to obtain toward desired applicability. This work therefore, will provide theoretical explanations on the variations of the molecular dipole moments, polarizability, $\mathrm{E}_{\mathrm{HOMO}}$ and $\mathrm{E}_{\mathrm{LumO}}$ (the frontier orbital energies), and UV absorptions of the various azobenzene chromophores. The $a b$ initio Hartree-Fock/Density Functional Theory calculations with bias with the Becke Three Lee Yang Parr (B3LYP) functional and a basis set $6-31 \mathrm{G}^{*}$ has proved to be the most used and reliable method in predicting the ground state electronic properties and molecular structure of organic systems $[13,14,15,24,26-28]$. The thermodynamic properties and the hyperpolarizabilities were predicted using the semi-empirical Austin Model 1 model.

\section{Computational Details}

The computational method used to study the electronic properties of the polymers is the ab initio restricted HF-DFT self consistent field (B3LYP) level of theory [29, 30, 31, 49] (DFT/B3LYP) for which the energy of a system is described as a function of the electronic density. Spartan14 [35] program package was used to run calculations on intel ${ }^{\circledR}$ Core (TM) i5-3317U CPU@1.70GHz 1.70Hz computer with the Becke Three Lee-Yang- Parr (B3LYP) exchange- correlation method [31]). It has been shown that this functional gives an adequate description of carbon-based materials. In order to obtain an accurate description of the physical system, the standard polarized $6-31 \mathrm{G}^{*}$ basis set [36-38] was used to investigate the electronic properties of the modeled compounds. Structural optimization was done without any constraints. It has been shown that B3LYP/6-31G* gives decent ground state structures of conjugated polymers [32]. For this work, semi-empirical Austin Model 1 (AM1) [33] as well as DFT/B3LYP/6-31G* calculations were carried out on them.

\subsection{Dipole Moments $(\mu)[12,23,26]$}

The knowledge of the intermolecular forces helps us to get a clear picture of the interaction between atoms in same or different kind of molecules. Dipole moment, $\mu$, is the 
measure of net polarity, which is the product of the charge, $\mathrm{Q}$, at the end of the molecular dipole and the distance, $r$, between the charges. That is it tells us about the charge separation in a molecule.

$$
\mu=\mathrm{Qxr}
$$

Electric dipole moment is a measure of the electrical polarity of a system of charges, be it an electron or a molecule. It is used to study the intermolecular interactions involving non-bonded type dipole-dipole interactions because the higher the dipole moment, the stronger will be the intermolecular interactions [34]. It has been found to increase with a decrease in the HOMO-LUMO energy gap of molecular systems [14].

\subsection{Polarizability ( $\alpha$ )}

This is a property of matter that measures the ability of a molecule to be polarized. That is, it measures the response of a molecule to external fields. Electric polarizability measures the tendency of a charge distribution to be distorted from its normal shape by an external field [39]. The electronic probability, $\alpha$, is defined as the ratio of the induced dipole moment, $\mu^{*}$, of an atom to the electric field, $\boldsymbol{\varepsilon}$, that produces the dipole moment [40]. $\varepsilon$ is the strength of the electric field and therefore vary proportionally with the induced dipole moment $\mu^{*}$;

$$
\mu^{*}=\alpha \varepsilon
$$

where $\alpha$ is the polarizability of the molecule measured in C. $\mathrm{m}^{2} \mathrm{~V}^{-1}$. It increases as the volume occupied by electrons increases, this is because the control the nuclear charge has on charge distribution becomes lesser as the number of electrons is increased [14].

$$
\alpha=\frac{2(q R)^{2}}{\Delta E}
$$

According to equation (2.3), it is also found out that it increases with a decreased band gap between the $\mathrm{E}_{\mathrm{HOMO}}$ and E

\subsection{Frontier Orbitals ( $\boldsymbol{E}_{\text {Hомо }}$ and $\left.E_{L U M O}\right)$}

Highest Occupied Molecular Orbital energy $\left(\mathrm{E}_{\mathrm{HOMO}}\right)$ and Lowest Unoccupied Molecular Orbital energy ( $\left.\mathrm{E}_{\mathrm{LUMO}}\right)$, also called the frontier orbitals, determine the interaction of the molecules with other species. The HOMO is the orbital that could act as an electron donor, since it is the outermost (highest energy) orbital containing electrons while the LUMO is the orbital that could act as the electron acceptor, since it is the innermost (lowest energy) orbital that has room to accept electrons. According to the frontier molecular orbital theory, the formation of a transition state is due to an interaction between the frontier orbitals (HOMO and LUMO) of reactants. According to Koopman's theorem associated within the framework of Hartree Fock's self consistent field molecular orbital theory, the ionization energy and electron affinity can be expressed through HOMO and LUMO energies. The energy of the HOMO is directly related to the ionization potential [41];

$$
I=-E_{\text {номо }}
$$

and the energy of the LUMO was generalized to also be directly related to the electron affinity;

$$
A=-E_{\text {LUMO }}
$$

The HOMO-LUMO gap is an important stability index. A large HOMO-LUMO gap implies low stability for the molecule in chemical reactions as the stabilization energy is inversely proportional to the energy gap. The concept of "activation hardness" has been also defined on the basis of the HOMO-LUMO energy gap. The qualitative definition of hardness is closely related to the polarizability, since a decrease of the energy gap usually leads to easier polarization of the molecule [42, 43]. Generally, HOMO energy level and LUMO energy levels depend on the electron-donating strength of donor and the electron-withdrawing strength of acceptor, respectively [44].

$$
\begin{aligned}
\Delta E & =I-A \\
& =E_{\text {LUMO }}-E_{\text {Hомо }}
\end{aligned}
$$

where $\mathrm{E}_{\mathrm{LUMO}}$ and $\mathrm{E}_{\mathrm{HOMO}}$ are the energies associated with the lowest unoccupied molecular orbital and the highest occupied molecular orbital respectively.

\section{Results and Discussion}

\subsection{Results}

The results of the DFT/B3LYP/6-31G* calculations for the ground state geometric properties (dihedral angles) for all the studied compounds are summarized in tables 1 . The molecular energies, dipole moments, polarizabilities, frontier orbitals and other electronic properties of the studied compounds in different solvents (vacuum, diethylether, acetone, ethanol and water) and with different substituents (B, C, D, E, F and G) are summarized in tables 2 and 3. The UV absorption wavelengths are recorded and summarized in table 4 .

\subsection{Discussion}

\subsubsection{Geometry Properties}

The bond distances and dihedral angles were calculated using DFT/B3LYP/6-31G*, there are no observable changes as the molecules were optimized in different solvents but there were observable changes in both the bond distances and dihedral angles as different substituents were introduced. Since there is no observable difference in the dihedral angles for molecule $\mathrm{A}$ in different solvents, that is, the molecule A is inclined to their aromatic ring planes at almost the same angles, this shows that the $-\mathrm{N}=\mathrm{N}$ - group of the studied molecules is planar with the aromatic ring and were only distorted as different substituent groups are introduced. That 
is why in table 4 , the molecules B, C, D, E, F, G and $\mathrm{H}$ inclined to their aromatic planes, especially for $\mathrm{N}_{3}-\mathrm{N}_{2}-\mathrm{C}_{4}-\mathrm{C}_{5}$ and $\mathrm{N}_{3}-\mathrm{N}_{2}-\mathrm{C}_{4}-\mathrm{C}_{3}$ angles. There is a drastic alteration in the displacement (torsional angles between the substituted azobenzene with the torsional angles of molecule $\mathrm{G}$ and $\mathrm{H}$ $8.65^{\circ}$ and $-5.95^{\circ}$ respectively. That is their planarity has greatly increased. It is of note that this is in accordance with the free electron molecular orbital approximation [45], which states that the band gap of molecules decrease with increased molecular size and planarity.

\subsubsection{Electronic Properties}

The importance of band gap engineering cannot be downplayed in modern technologies as it has been referred to in various articles and it is also an interesting topic. The band gap is the energy difference between the highest occupied molecular orbital (HOMO) and the lowest unoccupied molecular orbital (LUMO). It measures the electron density hardness and determines the molecular admittance in that molecules with high hardness (high $\Delta \mathrm{E}$ ) are termed hard molecules and those with low hardness (low $\Delta \mathrm{E}$ ) are termed soft molecules [46]. Results show that there is a slight difference in the band gaps of the molecules in different solvents, the highest difference coming from acetone (table 2). But as different substituents are added to the azobenze molecule there is a gradual reduction in the band gap, molecule $\mathrm{H}$ has the lowest band gap of $0.46 \mathrm{eV}$, and this is due to the replacement chlorine with iodine in molecule G. This is in line with Shikarawa's work [47], where he doped polyacetylene with iodine to increase its conductivity. This is because the gap between the HOMO and LUMO is greatly reduced and allowseasy flow of electrons from the HOMO (electron donor) to the LUMO (electron acceptor). It is observed that the band gap of these molecules reduced as the dipole moment, polarizability, molecular size and planarity increase. The molecule with the lowest band gap $(G)$ happens to be the one with the highest polarizability and dipole moment. It also has the highest molecular size and the highest planarity. This means that the molecule is the most reactive, most polarizable, highest electro-optic response and it is the softest.

The UV absorptions $\left(\lambda_{\text {abs }}\right)$ in table 4 show that compound $\mathrm{G}$ is mostly red-shifted with the most intense absorption band at $401.13 \mathrm{~nm}$. All studied molecules have are absorbed above $200 \mathrm{~nm}$, that is the energy transitions present are $n-\pi^{*}$ and $\pi$ $\pi^{*}$ and therefore, any electron promotion will be from the HOMO, usually the singlet ground state $\left(\mathrm{S}_{0}\right)$, to the LUMO $\left(\mathrm{S}_{1}\right)$. The most known stable and bright chromophores absorb and emit in the wavelength range of 300 and $700 \mathrm{~nm}$. As absorption is increased, it is always observed that the energy difference $\mathrm{S}_{1}$ and $\mathrm{S}_{0}$. This is also exhibited by all studied molecules, though the trend is not too noticeable in different solvent media but with different substituents, the absorption increased with decreased band gap.

Table 1. Results of DFT/B3LYP/6-31G* calculations on some selected dihedral angles of compound $A$ in vacuum, acetone, ethanol, water and diethylether and for $B, C, D, E, F, G$ and $H$. All dihedral angles were measured in $\left({ }^{\circ}\right)$.

\begin{tabular}{llll}
\hline Compounds/solvent & $\mathbf{N}_{\mathbf{3}}-\mathbf{N}_{2}-\mathbf{C}_{4}-\mathbf{C}_{5}$ & Molecule & $\mathbf{N}_{\mathbf{3}}-\mathbf{N}_{\mathbf{2}}-\mathbf{C}_{\mathbf{4}}-\mathbf{C}_{5}$ \\
\hline A/vacuum & 0.01 & $\mathrm{C}$ & 0.15 \\
A/diethylether & 0.01 & $\mathrm{D}$ & 1.40 \\
A/ethanol & 0.00 & $\mathrm{E}$ & 0.35 \\
A/water & 0.00 & $\mathrm{~F}$ & 0.26 \\
A/acetone & 0.00 & $\mathrm{G}$ & 171.35 \\
B & -0.25 & $\mathrm{H}$ & -174.05 \\
\hline
\end{tabular}

$\mathrm{A}=$ trans-azobenzene; $\mathrm{B}=4$-Hydroxy-azobenzene, $\mathrm{C}=4$-Amino-azobenzene, $\mathrm{D}=4$-Nitro-4'-hydroxy-azobenzene, $\mathrm{E}=3$,5-Dimethyl-4-(4'-nitrophenylazo)phenol, F= 2,5-Dimethyl-4-(4'-nitrophenylazo)-phenol, $\mathrm{G}=$ 2,5-Dimethyl-4(2'-chloro-4'-nitrophenylazo)-phenol, $\quad \mathrm{H}=\quad$ 2,5-Dimethyl-4-(2'iodo-4'nitrophenylazo)-phenol

Table 2. Results of B3LYP/6-31G* calculations on the electronic properties of compound A in vacuum, acetone, ethanol, water and diethylether.

\begin{tabular}{|c|c|c|c|c|c|c|c|c|c|}
\hline Compounds/solvent & Energy(a.u) & $\mathbf{E}_{\text {LUMo }}(\mathrm{eV})$ & $\mathbf{E}_{\text {номо }}(\mathrm{eV})$ & $\mathbf{I}(\mathrm{eV})$ & $\mathrm{A}(\mathrm{eV})$ & $\Delta E(e V)$ & $\eta(e V)$ & $\mu(D)$ & $\alpha()$ \\
\hline A/vacuum & -572.76 & -2.17 & -6.12 & 6.12 & 2.17 & 3.95 & 1.98 & 0.00 & 56.88 \\
\hline A/diethylether & -572.78 & -2.34 & -6.25 & 6.25 & 2.34 & 3.91 & 1.96 & 0.00 & 56.89 \\
\hline A/ethanol & -572.78 & -2.44 & -6.33 & 6.33 & 2.44 & 3.89 & 1.95 & 0.00 & 56.89 \\
\hline $\mathrm{A} /$ water & -572.77 & -2.46 & -6.34 & 6.34 & 2.46 & 3.88 & 1.94 & 0.00 & 56.90 \\
\hline A/acetone & -572.78 & -2.41 & -6.28 & 6.28 & 2.41 & 3.87 & 1.94 & 0.00 & 56.90 \\
\hline
\end{tabular}

$\mathrm{A}=$ trans-azobenzene.

Table 3. Results of B3LYP/6-31G* calculations on the electronic properties of compound B, C, D, E, F, G and $H$.

\begin{tabular}{|c|c|c|c|c|c|c|c|c|c|}
\hline Compounds & Energy(a.u) & $E_{\text {LUMo }}(\mathrm{eV})$ & $\mathbf{E}_{\text {номо }}(\mathrm{eV})$ & $\mathrm{I}(\mathrm{eV})$ & $\mathrm{A}(\mathrm{eV})$ & $\Delta E(e V)$ & $\eta(\mathrm{eV})$ & $\mu(D)$ & $\alpha()$ \\
\hline B & -647.98 & -2.02 & -5.77 & 5.77 & 2.02 & 3.75 & 1.88 & 1.51 & 57.50 \\
\hline $\mathrm{C}$ & -628.19 & -1.82 & -5.37 & 5.37 & 1.82 & 3.55 & 1.78 & 3.12 & 57.81 \\
\hline $\mathrm{D}$ & -852.48 & -2.90 & -6.28 & 6.28 & 2.90 & 3.38 & 1.69 & 7.20 & 59.33 \\
\hline E & -931.11 & -2.82 & -6.15 & 6.15 & 2.82 & 3.33 & 1.67 & 7.30 & 62.22 \\
\hline $\mathrm{F}$ & -931.12 & -2.84 & -6.08 & 6.08 & 2.84 & 3.24 & 1.62 & 7.73 & 62.31 \\
\hline G & -1390.71 & -3.01 & -6.16 & 6.16 & 3.01 & 3.15 & 1.58 & 8.02 & 63.44 \\
\hline
\end{tabular}

$\mathrm{B}=4$-Hydroxy-azobenzene, $\mathrm{C}=4$-Amino-azobenzene, $\mathrm{D}=4$-Nitro-4'-hydroxy-azobenzene, $\mathrm{E}=3$,5-Dimethyl-4-(4'-nitrophenylazo)-phenol, $\mathrm{F}=2$,5-Dimethyl-4(4'-nitrophenylazo)-phenol, G= 2,5-Dimethyl-4-(2'-chloro-4'-nitrophenylazo)-phenol, H= 2,5-Dimethyl-4-(2'iodo-4'-nitrophenylazo)-phenol 

on the Electronic, Geometric and Spectroscopic Properties of Azobenzene and Some Substituted Derivatives

Table 4. Results of the absorption wavelength $\left(\lambda_{\text {abs }}\right)$ obtained by DFT/B3LYP/6-31G* for compounds a in different solvents.

\begin{tabular}{llllll}
\hline Compounds/solvent & $\begin{array}{l}\text { Wavelength/nm } \\
\text { (intensity) }\end{array}$ & Wavelength/nm (intensity) & Compounds & $\begin{array}{l}\text { Wavelength/nm } \\
\text { (intensity) }\end{array}$ & $\begin{array}{l}\text { Wavelength/nm } \\
\text { (intensity) }\end{array}$ \\
\hline A/vacuum & $297.75(0.12)$ & $309.75(1.03)$ & $\mathrm{C}$ & $266.27(0.09)$ & $339.73(1.25)$ \\
A/diethylether & $305.22(0.26)$ & $314.78(0.94)$ & $\mathrm{D}$ & $307.53(0.04)$ & $367.34(1.09)$ \\
A/ethanol & $307.24(0.33)$ & $316.27(0.88)$ & $\mathrm{E}$ & $336.69(0.02)$ & $371.35(1.11)$ \\
A/water & $307.62(0.35)$ & $315.56(0.86)$ & $\mathrm{F}$ & $339.41(0.08)$ & $382.29(1.03)$ \\
A/acetone & $307.77(0.35)$ & $316.80(0.87)$ & $\mathrm{G}$ & $333.38(0.03)$ & $392.56(1.01)$ \\
B & $260.36(0.03)$ & $325.51(1.16)$ & $\mathrm{H}$ & $368.19(0.22)$ & $401.13(0.81)$ \\
\hline
\end{tabular}

$\mathrm{A}=$ azobenzene; $\mathrm{B}=4$-Hydroxy-azobenzene, $\mathrm{C}=4$-Amino-azobenzene, $\mathrm{D}=4$-Nitro-4'-hydroxy-azobenzene, $\mathrm{E}=3$ 3,5-Dimethyl-4-(4'-nitrophenylazo)-phenol, $\mathrm{F}=$ 2,5-Dimethyl-4-(4'-nitrophenylazo)-phenol, G= 2,5-Dimethyl-4-(2'-chloro-4'-nitrophenylazo)-phenol, H= 2,5-Dimethyl-4-(2'iodo-4'-nitrophenylazo)-phenol.

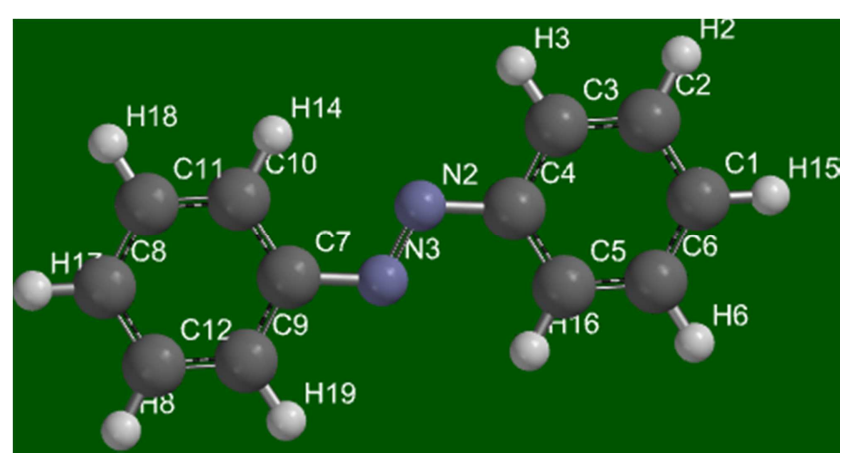

Fig. 1. Optimized structure of compound A.

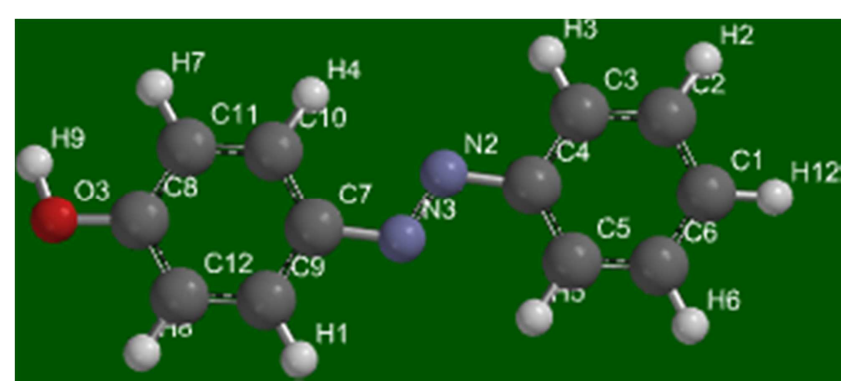

Fig. 2. Optimized structure of compound B.

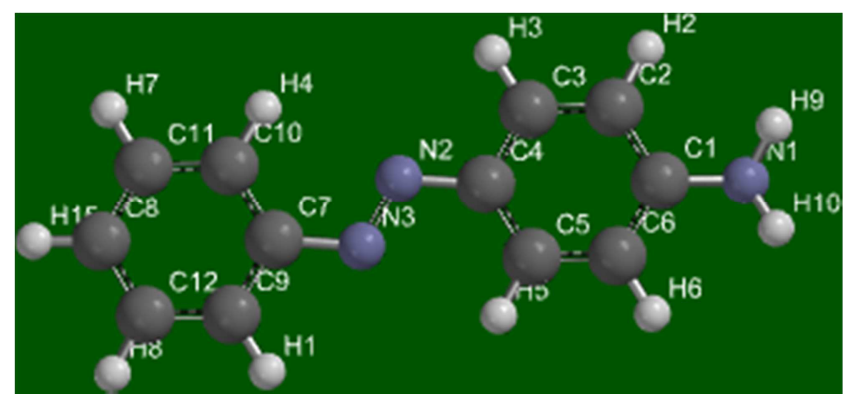

Fig. 3. Optimized structure of compound C.

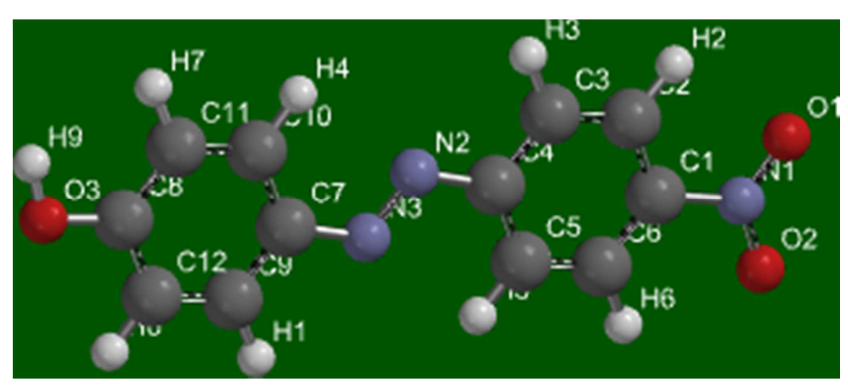

Fig. 4. Optimized structure of compound D.

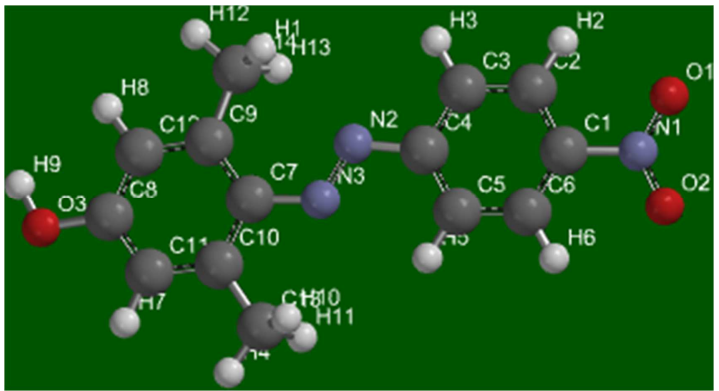

Fig. 5. Optimized structure of compound E.

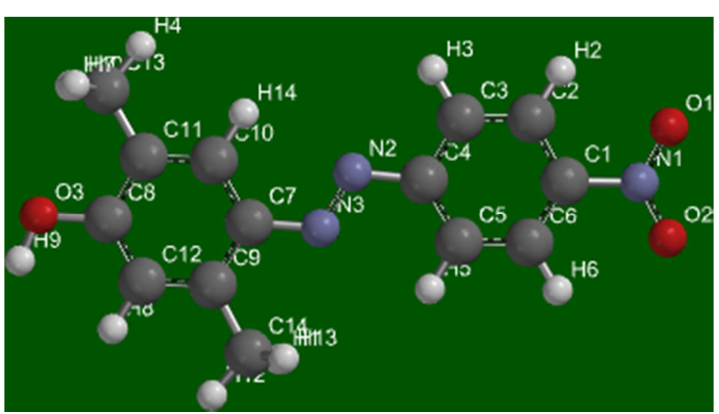

Fig. 6. Optimized structure of compound F.

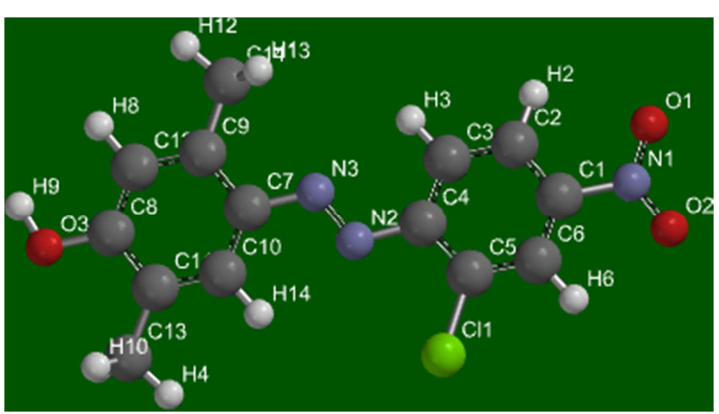

Fig. 7. Optimized structure of compound G.

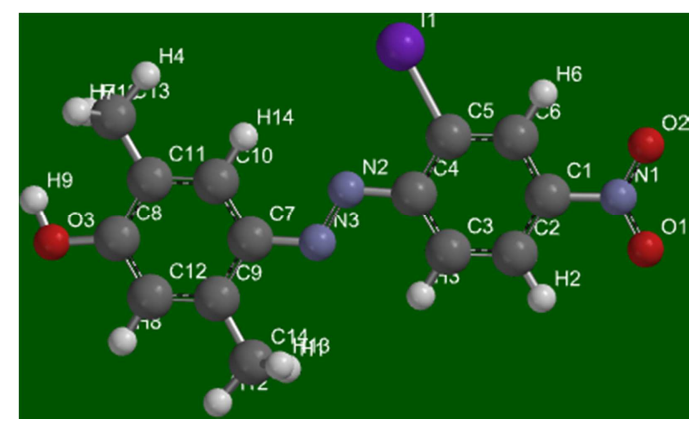

Fig. 8. Optimized structure for compound $\mathrm{H}$. 


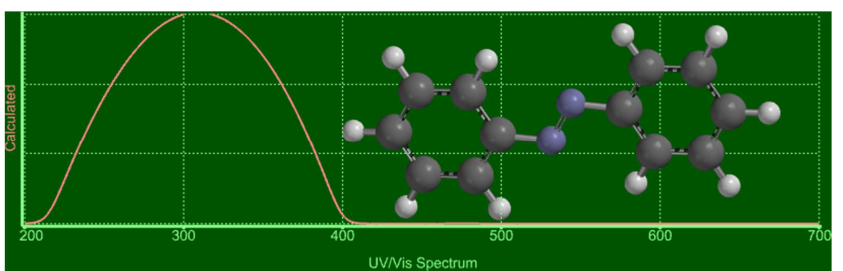

Fig. 9. UV spectrum of compound A in vacuum.

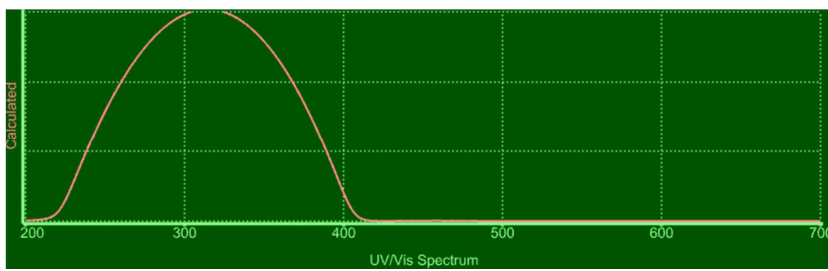

Fig. 10. UV spectrum of compound A in acetone.

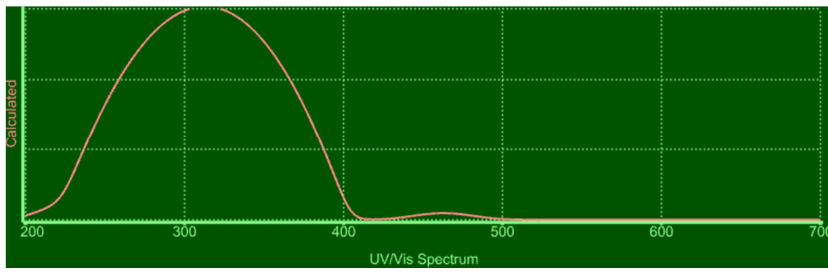

Fig. 11. UV spectrum of compound A in diethylether.

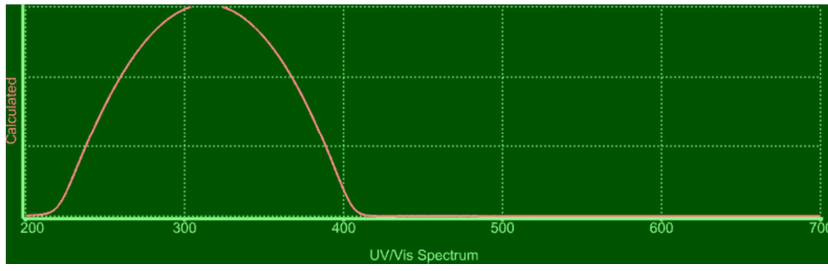

Fig. 12. UV spectrum of compound A in ethanol.

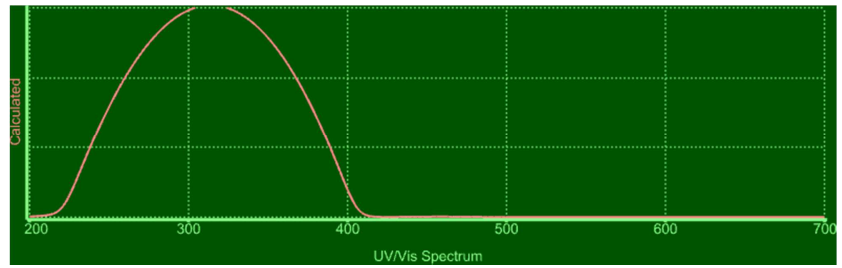

Fig. 13. UV spectrum of compound A in water.

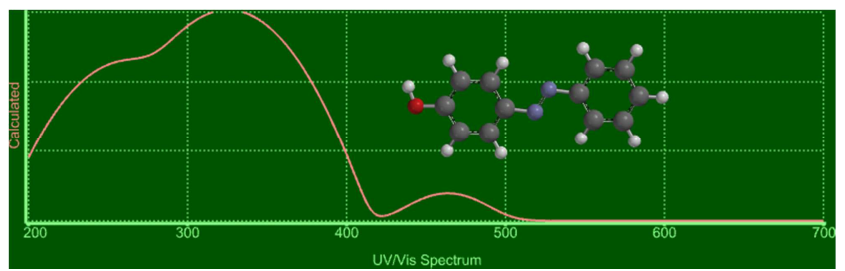

Fig. 14. UV spectrum for compound B.

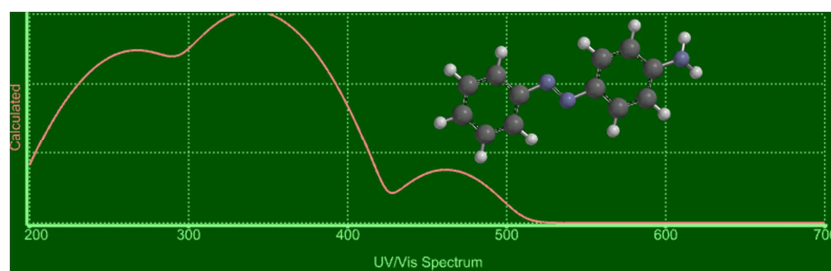

Fig. 15. UV spectrum for compound C.

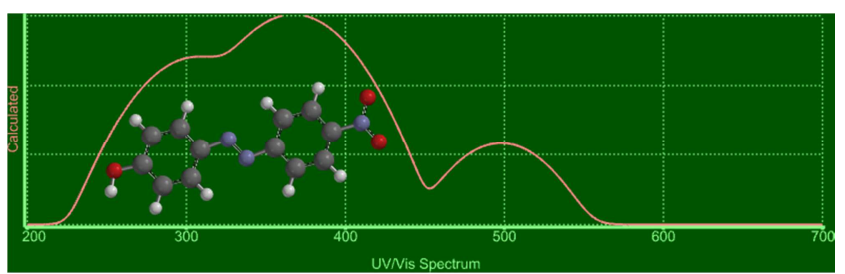

Fig. 16. UV spectrum of compound D.

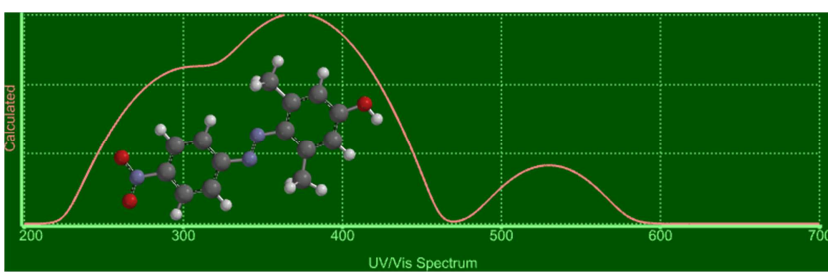

Fig. 17. UV spectrum for compound E.

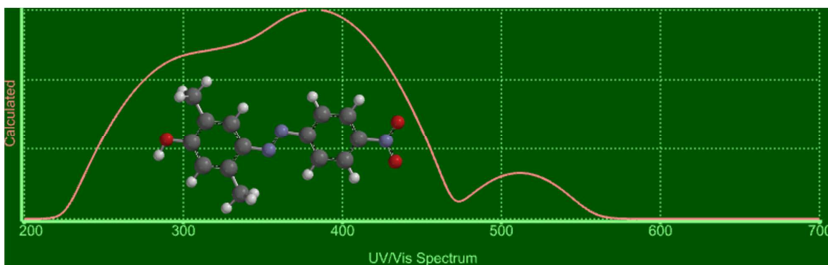

Fig. 18. UV spectrum of compond F.

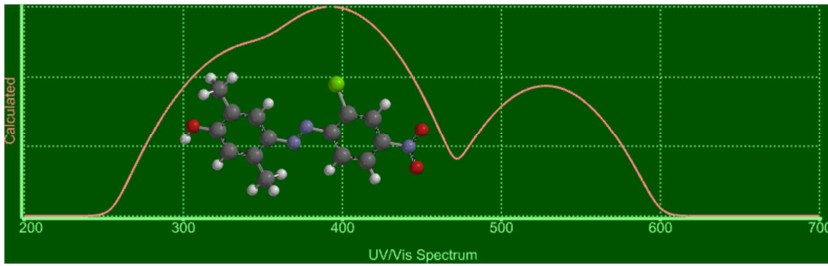

Fig. 19. UV spectrum of compound G.

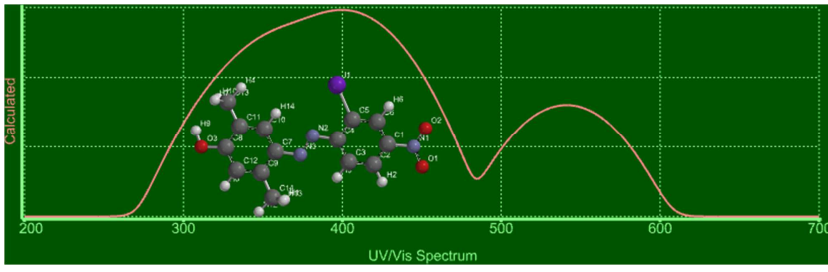

Fig. 20. UV spectrum for compound $H$.

\section{Conclusion}

Theoretical calculations have been carried out on azobenzene chromophores. Their electronic properties and geometric properties have been keenly studied in different solvent media and with the introduction of different substituting groups. It is of note that among all these molecules, H (2,5-Dimethyl-4-(2'iodo-4'-nitrophenylazo)phenol) is the most planar, with the highest molecular size, lowest band gap $(0.46 \mathrm{eV})$, highest dipole moment (875.02D) and polarizability $\left(64.97 \mathrm{C} . \mathrm{m}^{2} \mathrm{~V}^{-1}\right)$, it also has the highest absorption $(401.13 \mathrm{~nm})$. That is, it has the best nonlinearity, when compared to others. The changes that occurred as different solvents and substituents were added are what we investigated here and it was observed that 
obvious changes occurred as different substituents were added but with different solvents, only little changes were observed. Because compound $\mathrm{H}$ has the lowest band gap and consequently, the softest, highest dipole moment, highest polarizability and it was red-shifted the most from the undoped azobenzene, it is suggested that it can be used for electronic applicabilities.

\section{Acknowledgement}

We wish to express our profound gratitude to the Senate, University of Ibadan, Oyo State for making available research grant and for also creating an enabling and conducive environment for this research work.

\section{References}

[1] Salem AH, Jordan Journal of Chemistry. (2) 2007, 133-144.

[2] Armstrong GR, Clarkson J and Smith WEW, Journal. Phys. Chem. (99) 1995, 17825-17831.

[3] Hosseinnezhad M, Khosravi A, Garanjig K and Moradian S, The comparison of spectra and dyeing properties of new azonaphthalimide with analogue azobenzene dyes on natural and synthetic polymers. Arabian Journal of Chemistry. 2014.

[4] Aktan E, Babur B, Seferoglu Z, Hokelek T and Sahin E, J. Mol. Stru., (2) 2011, 113-120.

[5] Rau H, 1990. Rabek, JF., ed. Photochemistry and Photophysics 2. Boca Raton, FL: CRC Press. 2011, 119-141.

[6] Yager KG and Barrett, CJ, "Chapter 17 - Azobenzene Polymers as Photomechanical and Multifunctional Smart Materials". In Shahinpoor, M, Schneider HJ, Intelligent Materials. Cambridge: Royal Society of Chemistry. 2008, 426-427.

[7] Hartley GS, The cis-form of azobenzene. Nature. 140 1937, 281.

[8] Torres-Zúñiga V, Morales-Saavedra OG, Rivera E, CastañedaGuzmán R, Bañuelos, JG and Ortega-Martínez R, "Preparation and photophysical properties of monomeric liquid-crystalline azo-dyes embedded in bulk and film $\mathrm{SiO} 2-$ sonogel glasses". Journal of Sol-Gel Science and Technology 56 (1) $2010,7-18$.

[9] Faustino H, El-Shistawy RM, Reis LV, Santos PF and Almeida P, Tetrahedron Letters. (49) 2008, 6907-6909.

[10] Cui Y, Qian G, Gao, J, Chen L, Wang Z and Wang M, Preparation and Nonlinear Optical Properties of InorganicOrganic Hybrid films with Various Substituents on Chromophores. J. Phys. Chem. B. (109) 2005, 23295-23299.

[11] Lee YO, Pradhan T, No K and Kim, JS, N, N-Dimethylaniline and 1-(trifluoromethyl) benzene-functionalized tetrakis (ethynyl) pyrenes: synthesis, photophysical, electrochemical and computational studies. Tetrahedron. (68) 2012, 17041711.

[12] Islam MM, Bhiuyan MDH, Bredow $\mathrm{T}$ and Try $\mathrm{AC}$, Theoretical investigation of the nonlinear optical properties of substituted anilines and N, N-Dimethylanilines. Comput. Theor. Chem. (967) 2011, 165-170.
[13] Grozema FC, Telesca R, Jonkman HT, Siebbeles LDA and Snijders JG, Excited state polarizabilities of conjugated molecules calculated using time dependent density functional theory. J. Chem. Phys. (115) 2001, 10014-10021.

[14] Targema M, Obi-Egbedi NO and Adeoye MD, Molecular structure and solvent effects on the dipole moments and polarizabilities of some aniline derivatives. Computational and Theoretical Chemistry. (1012) 2013, 47-53.

[15] Adejoro IA, Ibeji CU and Aigbe AE, Theoretical study on substituent effect on the properties of Benzofused thieno [3,2b] furan and its isomeric form. Nature and Science. (11) 2013, $75-82$.

[16] Yitzchaik S and Marks T, J. Acc. Chem. Res. (29)1996, 197.

[17] Levy D, Esquivias. Adv. Mater. (7) 1995, 120.

[18] Sisido M, Ishikawa Y, Harada M and Ito K, Macromolecules. (24)1991), 3999.

[19] Jung C, Takehisa C, Sakata Y and Kaneda T, Chem Lett. 1996, 147.

[20] Yamamura H, Kawai H, Yotsuya T, Higuchi T, Butsugan Y, Araki S, Kawai M and Fujita K. Chem. Lett. 1996, 799.

[21] Liu X, Bruce D and Manners I, Chem. Commun.1997, 289.

[22] Junge, D and McGrath D, Chem. Commun.1997, 857.

[23] Omar MA, Elementary Solid State Physics, 1974, Chapt. 8, Addison Wesley, London.

[24] Kavitha E, Sundaraganesan N and Sebastian S, Molecular structure, vibrational soectroscopy and HOMO, LUMO studies of 4-nitroaniline by density functional theory method. Indian Journal of Pure and Applied Physics. (48) 2010, 20-30.

[25] Sridevi C, Shanthi G and Velraj G, Structural, vibrational, electronic, NMR and reactivity analyses of 2-amino-4Hchromene-3-carbonitrile (ACC) by ab initio HF and DFT calculations, Spectrochem. Acta. Part A (89) 2012, 46-54.

[26] Milman V, Refson K, Clark SJ, Pickard CJ, Yates KR, Gao SP, Hasnip PJ, Probert MIJ, Perlov A and Segall MD, Electron and Vibrational Spectroscopies using DFT, plane waves and pseudopotentials: CASTEP implementation. J. Mol. Struc. (THEOCHEM). (954) 2010, 22-35.

[27] (a) Jursic BS and Can J, Theoretical study on Benzofused thieno [3, 2-b] Furan bromination mechanism. Chemistry. (74) 1996,114. (b) Jursic BS and Zdravskovski Z, Theoretical study of benzofused [3, 2-b] furans in the reaction with electrophiles. Int. J. Quantum Chemistry. (54) 1994, 161.

[28] Nathaniel R, Mineva T, Nikolova R and Bojilova A, Density Functional Study of the interaction of (3-bromoacetyl) coumarin with phosphate. Int. J. Quantum Chemistry. (106) 2006, 1357.

[29] Hohenberg $\mathrm{P}$ and Kohn W, Inhomogeneous electron gas, Phys. Rev. 136B1964, 864-871.

[30] Kohn W and Sham LJ, Phys. Rev. 140A 1965, 1133.

[31] Becke AD, Density Functional Thermochemistry. III. The role of exact exchange. J. Chem. Phys. (98) 1993 5648-5652.

[32] Hotta S, Kimura H, Lee SAT and Tamaki T, J. Heterocycl. Chem. (37) 2000, 281. 
[33] Dewar M, Thiel W, Semi Empirical Quantum Chemistry. J. Am. Chem. Soc. (99)1977, 4499.

[34] McMurryF, Chemistry fourth edition. Pearson Education. New Jersey. 2002.

[35] Shao Y, Molnar LF, Jung Y, Kussmann J, Ochsenfeld C, Brown ST, Gilbert ATB, Slipchenko LV, Levchenko SV, O’Neill DP, DiStasio Jr RA, Lochan RC, Wang T, Beran GJO, Besley NA, Herbert JM, Lin CY, Van Voorhis T, Chien SH, Sodt A, Steele RP, Rassolov VA, Maslen PE, Korambath PP, Adamson RD, Austin B, Baker J, Byrd EFC, Dachsel H, Doerksen RJ, Dreuw A, Dunietz BD, Dutoi AD, Furlani TR, Gwaltney SR, Heyden A, Hirata S, Hsu CP, Kedziora G, Khalliulin RZ, Klunzinger P, Lee AM, Lee MS, Liang WZ, Lotan I, Nair N, Peters B, Proynov EI, Pieniazek PA, Rhee YM, Ritchie J, Rosta E, Sherrill CD, Simmonett, AC, Subotnik JE, Woodcock III HL, Zhang W, Bell AT, Chakraborty AK, Chipman DM, Keil FJ, Warshel A, Hehre WJ, Schaefer HF, Kong J, Krylov AI, Gill PMW, HeadGordon M, Deepmer BJ, Driessen AJ, Hehre TS, Johnson JA, Pietro WJ, Yu J, SPARTAN '10, build 1.01 Wavefunction Inc. Irvine CA, 2011.

[36] Gece $G$, The use of quantum chemical methods in corrosion inhibitor studies. Corros. Sci. (50) 2008, 2981-2992.

[37] Atkins PW and Friedman RS, Molecular Quantum Mechanics, Fourth edition. University Press, New York. 2004.

[38] Ramachandran RE, Deepa $G$ and Namboori $K$, Computational Chemistry and Molecular Modelling: Principles and Applications. Springer-Verlag. Berlin Heidelberg. 2008.

[39] Zhou L, Lee FX, Wilcox W and Christensen J, Magnetic polarizability of hadrons from lattice. QCD. European Organization for Nuclear Research. (CERN). 2002.
[40] Introduction to Electrodynamics (3rd Edition), Griffiths DJ, Pearson Education, Dorling Kindersley, 2007.

[41] Koopmans T, "Uber die Zuordnung von Wellenfunktionen und Eigenwerten zu den Einzelnen Elektronen Eines atoms". Physica (Elsevier). 1 (1-6): 1990, 104-113.

[42] Zhou Z and Parr RG, Activation hardness: new index for describing the orientation of electrophilic aromatic substitution, J. Am. Chem. Soc. (112) 1990, 5720-5724.

[43] Lewis DFV, Ioannides C and Parke DV, Interaction of a series of nitriles with the alcohol-inducible isoform of P450: Computer analysis of structure-activity relationships, Xenobiotica 24: 1994, 401-408.

[44] Kikuchi O, Systematic QSAR procedures with quantum chemical descriptors, Quant. Struct.-Act. Relat. (6) 1987, 179 184.

[45] Motinger RG, Physical Chemistry, Third Ed., Elsevier Inc., USA, 2008.

[46] Meyer WH, Kiess H, Binggeli B, Meier E and Harbeke G, Polymer for use in information storage. Synth. Met. (10) 1985, 225-259.

[47] Shikarawa H, Louis EJ, MacDiarmid AG, Chiang CK and Heeger AJ, Chem. Comm. 1977, 578.

[48] Mingxin D, Amirhossein B, Subhas S, Andrew AB and Andrew GW. Red-Shifting Azobenzene Photoswitches for In Vivo use. Acct. Chem Res. 48 (10): 2015, 2662-2670.

[49] Ridhima C, Nandita $M$ and Sudhir K. Interaction of anthranilic acid with silver nanoparticles: A Raman, surfaceenhanced Raman scattering and density functional theoretical study. Journal of Molecular Structure. 1076. 2014, 35-41. 